University of Nebraska - Lincoln

DigitalCommons@University of Nebraska - Lincoln

\title{
Thermoreversible and remendable glass-polymer interface for fiber-reinforced composites
}

Amy M. Peterson

Drexel University

Robert E. Jensen

US Army Research Laboratory

Giuseppe R. Palmese

Drexel University, palmese@coe.drexel.edu

Follow this and additional works at: https://digitalcommons.unl.edu/usarmyresearch

Part of the Operations Research, Systems Engineering and Industrial Engineering Commons

Peterson, Amy M.; Jensen, Robert E.; and Palmese, Giuseppe R., "Thermoreversible and remendable glass-polymer interface for fiber-reinforced composites" (2011). US Army Research. 144.

https://digitalcommons.unl.edu/usarmyresearch/144

This Article is brought to you for free and open access by the U.S. Department of Defense at DigitalCommons@University of Nebraska - Lincoln. It has been accepted for inclusion in US Army Research by an authorized administrator of DigitalCommons@University of Nebraska - Lincoln. 


\title{
Thermoreversible and remendable glass-polymer interface for fiber-reinforced composites
}

\author{
Amy M. Peterson ${ }^{\mathrm{a}}$, Robert E. Jensen ${ }^{\mathrm{b}}$, Giuseppe R. Palmese ${ }^{\mathrm{a}, *}$ \\ a Department of Chemical and Biological Engineering, Drexel University, 3141 Chestnut Street, Philadelphia, PA 19104, USA \\ ${ }^{\mathrm{b}}$ US Army Research Laboratory, Weapons and Materials Research Directorate, Aberdeen Proving Ground, MD 21005, USA
}

\section{A R T I C L E I N F O}

\section{Article history:}

Received 14 July 2010

Received in revised form 20 October 2010

Accepted 24 November 2010

Available online 30 November 2010

\section{Keywords:}

A. Coupling agents

A. Functional composites

B. Fiber/matrix bond

B. Interphase

\begin{abstract}
A B S T R A C T
Adhesion of the reinforcement to the polymer matrix is essential for load transfer from the polymer matrix to the reinforcement material in fiber-reinforced composites. The reversible Diels-Alder reaction between a furan-functionalized epoxy-amine thermosetting matrix with a maleimide-functionalized glass fiber was used to impart remendability at the polymer-glass interface for potential application in glass fiber-reinforced composites. At room temperature the Diels-Alder adduct is formed spontaneously and above $90{ }^{\circ} \mathrm{C}$ the adduct breaks apart to reform the original furan and maleimide moieties. Healing of the interface was investigated with single fiber microdroplet pull-out testing. Following complete failure of this interface, significant healing was observed, with some specimens recovering over $100 \%$ of the initial properties. Healing efficiency was not affected by the distance of displacement, with an overall average of $41 \%$ healing efficiency. Up to five healing cycles were successfully achieved. It is expected that a glass fiber-reinforced composite of maleimide-sized glass within a furan-functionalized network will demonstrate extension of fatigue life.
\end{abstract}

(C) 2010 Elsevier Ltd. All rights reserved.

\section{Introduction}

Durability of composites depends on the integrity of the interface and the region known as the interphase between the matrix and the reinforcing material $[1,2]$. Adhesion of the reinforcement to the polymer matrix is essential for load transfer from the polymer matrix to the reinforcement material. However, the difference in mechanical properties between the matrix and reinforcement material makes the interphase region between the two a potential location for stress concentration and eventual crack formation, depending on the loading mode. Fatigue, whether mechanically or thermally induced, leads to growth of such cracks and is a major cause of mechanical failure in composites $[3,4]$. Surface treatments and application of a chemical sizing to the reinforcement material are options for improving interfacial adhesion and durability.

Improved interfacial properties reduce the effects of fatigue; however, failure is inevitable. If reversible covalent bonds can form between the polymer network and the reinforcement material, the interphase will be capable of healing, resulting in improved lifetime of the composite. We report the development of maleimide-functionalized glass surfaces that covalently bond thermoreversibly with network-bound furans through the Diels-Alder reaction. The reaction favors the product (Diels-Alder adduct)

\footnotetext{
* Corresponding author. Tel.: +1 215895 5814; fax: +1 2158955837 .

E-mail address: palmese@coe.drexel.edu (G.R. Palmese).
}

below $60{ }^{\circ} \mathrm{C}$ and the reactants (furan and malemide) above $90^{\circ} \mathrm{C}$. Between 60 and $90^{\circ} \mathrm{C}$ equilibria exist in relative concentrations of the products and reactants. Fig. 1 shows this reversible reaction with furans as red notched trapezoids, maleimides as blue triangles, and Diels-Alder adducts as purple trapezoids.

The Diels-Alder reaction was discovered in the 1920s and in the last decade was applied by Wudl and Coworkers, as the cross-linking mechanism in mendable polymers for healing applications [5-9]. After failure of these polymers $98 \%$ of the initial strength can be recovered through heating and subsequent cooling, which allows for cross-links to form across the crack surface. Recently, the authors of this report have selectively applied the Diels-Alder reaction of furan and maleimide to polymer composites so as to maintain the thermal stability of traditional thermosets while adding the healing ability of a thermoreversible reaction $[10,11]$. In one system, a reversibly cross-linked polymer gel was incorporated in particulate form within an epoxy-amine thermoset, while the other used compatible functionalization of the polymer network and healing agent to induce healing through covalent Diels-Alder bond formation. Other applications of the Diels-Alder reaction of furan and maleimide include thermally reversible hydrogels [12], recyclable polymers [13-17], and foamed polymeric encapsulants [18]. The Diels-Alder reaction is a powerful tool that has been discussed in numerous reviews [19-24].

Healing of sandwich structure core-skin disbonding has been achieved using a vascular approach [25]. Following impact 


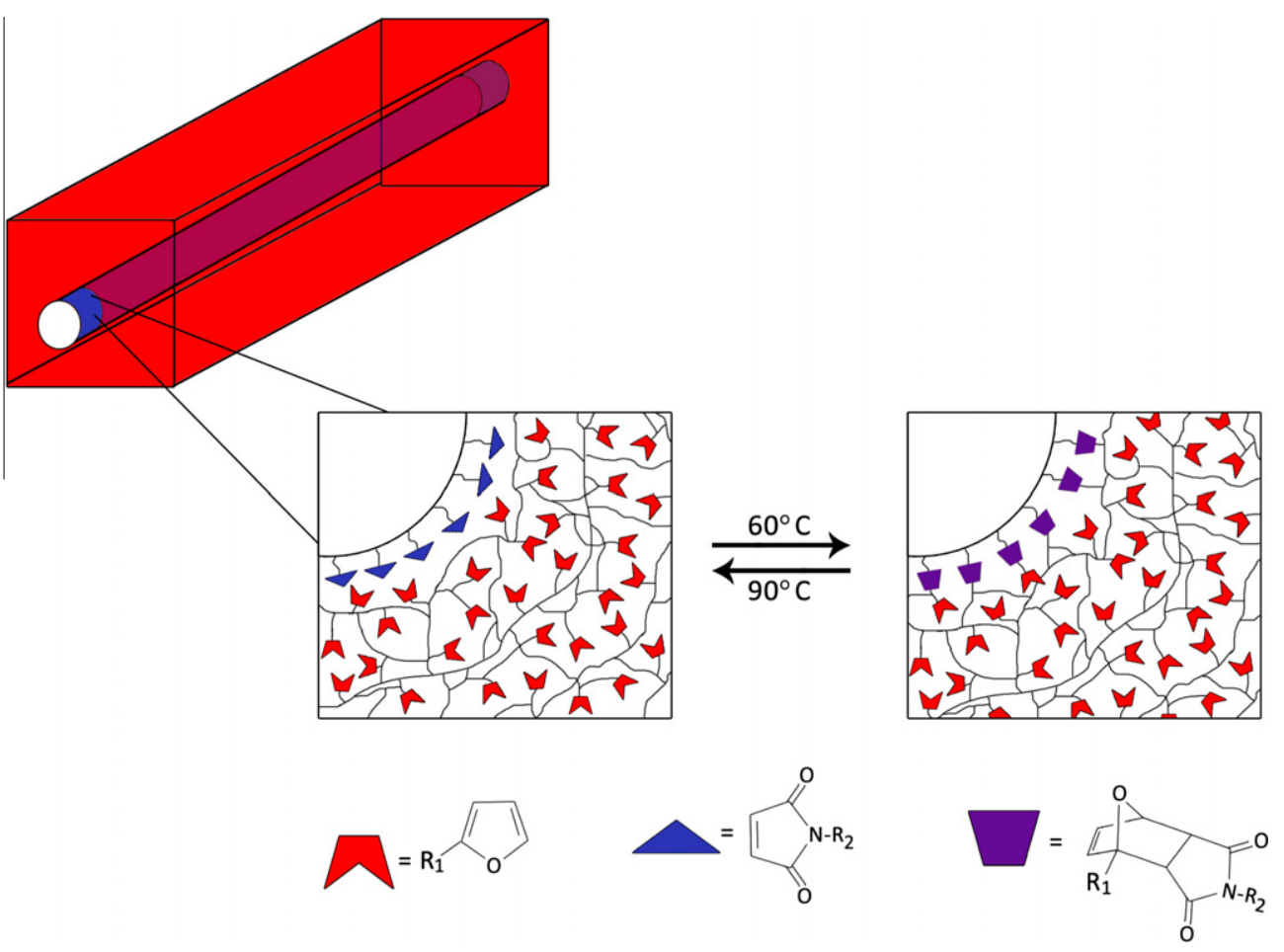

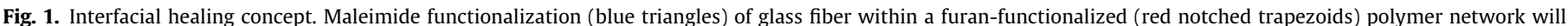

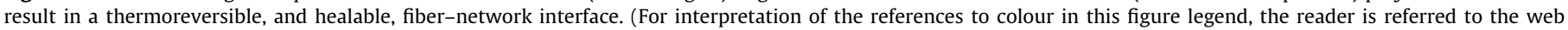
version of this article.)

damage, total recovery of strength was observed. Fiber-resin interfacial healing has been previously demonstrated by placing resinfilled nanocapsules and catalyst (if necessary to induce polymerization) on a fiber surface [26]. Upon failure, capsules rupture and the polymer fills and cures in the crack site, resulting in recovery of $44 \pm 5 \%$ in interfacial shear strength for the most effective system. While this method demonstrates autonomic fiber-matrix crack repair, healing is limited to once per fiber.

The system reported herein represents a simple and effective method for creating a fiber-reinforced composite with remendable interfaces. Fibers were sized using a two-step process to provide maleimide functionality and the polymer network was compatibly functionalized with furan groups, resulting in a thermoreversible fiber-network interface as shown in Fig. 1. Fiber functionalization was characterized using a variety of methods. The polymer network used has been previously used and is characterized extensively in the literature [11]. Interfacial healing was evaluated with single fiber microdroplet pull-out testing of functionalized and control systems.

It is generally understood that at the interface between a polymer and a functionalized reinforcing material there exists an interphase with a known thickness and gradient of properties [27-29]. For simplicity's sake, the terms interface and interphase will be used interchangeably in this communication.

\section{Material and methods}

\subsection{Polymer network preparation}

The furan-functionalized polymer used in this study was previously reported in the investigation of bismalemide solutions as room temperature healing agents [11]. The base polymer network investigated consisted of a 6:4 weight ratio of a diglycidyl ether of bisphenol-A (DGEBA with epoxide equivalent weight EEW $=185$ -
192, EPON 828, Miller-Stephenson) to furfuryl glycidyl ether (FGE, Sigma-Aldrich) with a stoichiometric amount of the amine curing agent 4,4'-methylene biscyclohexanamine (PACM, Air Products and Chemicals, Inc.).

To elucidate the effect of furan concentration on healing efficiency, polymer networks were prepared with the same cross-link density as the 6:4 DGEBA-FGE system but with varying amounts of furans. This was achieved by substituting phenyl glycidyl ether (PGE, Sigma-Aldrich) for FGE. PGE is identical to FGE except that it contains a pendant phenyl group instead of a pendant furan. As a result, the effect of furan loading in the network could be investigated while maintaining cross-link density and network structure by replacing FGE with a stoichiometric amount of PGE. Stoichiometric calculations were carried out using EEW $=188$ for DGEBA, 154 for FGE, and 164 for PGE, and an AHEW $=52.5$ for PACM. For example, a sample with the same cross-link density as the 6:4 DGEBA-FGE system but with half of the number of furan groups would be prepared by mixing $6.00 \mathrm{~g}$ of DGEBA, $4.00 * 1 / 2=2.00 \mathrm{~g}$ of $\mathrm{FGE}, 4.00 * 1 / 2 * 164 / 154=2.13 \mathrm{~g}$ of PGE, and $(6.00 / 188+2 / 154+2.13 / 164) * 52.5=3.04 \mathrm{~g}$ of PACM. Control healing studies were performed with a network in which there were no furans (no FGE). To prepare $13.43 \mathrm{~g}$ of this polymer, $6.00 \mathrm{~g}$ of DGEBA, $4.26 \mathrm{~g}$ of PGE, and $3.04 \mathrm{~g}$ of PACM were mixed. All polymer networks were cured at $60{ }^{\circ} \mathrm{C}$ for $2 \mathrm{~h}$ and postcured at $90{ }^{\circ} \mathrm{C}$ for $2 \mathrm{~h}$. Differential scanning calorimetry (DSC) showed complete reaction of these systems.

\subsection{Glass functionalization}

Water sized E-glass fibers with an average diameter of $23 \mu \mathrm{m}$ were kindly provided by Fiber Glass Industries, Inc. (Amsterdam, NY). Prior to use, fibers were cleaned in water, ethanol, and acetone to remove any impurities from processing or shipping. Borosilicate glass slides (Fisher Scientific) were cleaned by running through a 


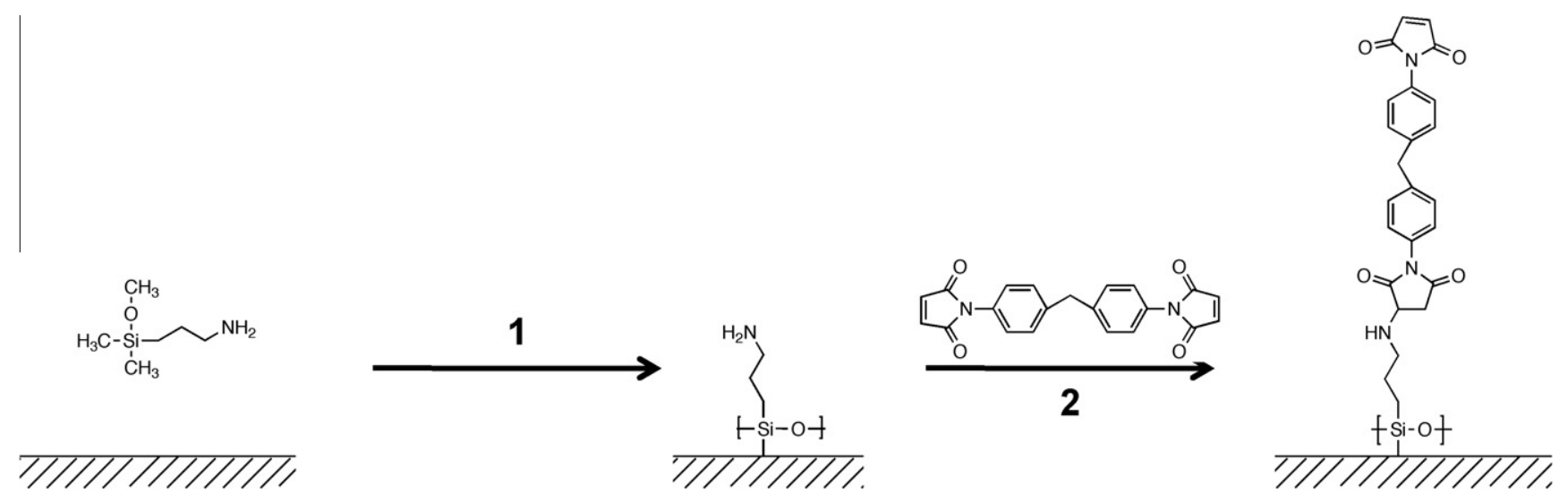

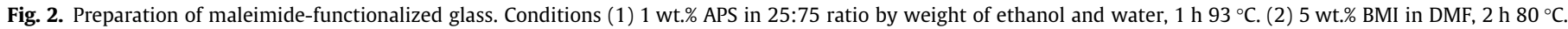

propane flame and then cleaning with acetone to remove any particulates.

Maleimide functionalization was carried out using a two-step process as shown in Fig. 2. First, a 1 wt.\% solution of 3-aminopropyltrimethoxysilane (APS, Gelest) in a 25:75 by weight ratio of ethanol and water was used to provide amine groups on the glass surface. Next, Michael Addition of malemides and amines provided maleimide functionality through the reaction of $1,1^{\prime}$-(methylenedi4,1-phenylene)bismaleimide (BMI, Sigma-Aldrich) in N,N'-dimethylformamide (DMF, Sigma-Aldrich) with surface amines [30]. Given the short and rigid structure of BMI, Michael Addition of both maleimides on a molecule of BMI ("backbiting") should be minimal. For fiber functionalization, fibers were dipped in the reaction solution and reacted under the proscribed conditions. The reaction solution was spin coated onto glass slides. Silanation took place at $93{ }^{\circ} \mathrm{C}$ for $1 \mathrm{~h}$, while maleimide functionalization required 2 h at $80^{\circ} \mathrm{C}$.

\subsection{Glass characterization}

Functionalized glass was characterized using two methods: atttenuated total reflectance-Fourier transform infrared (ATR-FTIR) spectroscopy and contact angle analysis. A Thermo-Nicolet Nexus 870 FT-IR with a single bounce Silver Gate ATR with ZnSe crystal from Specac was used for ATR-FTIR spectroscopy of glass slides. Static contact angle were measured using a KSV Instruments CAM 200 as a characterization method for glass slides. Glass fibers were characterized with a Thermo Scientific Cahn DCA dynamic contact angle system. Surface energies were calculated with contact angle values for water, diiodomethane, glycerol, and formamide as the liquid phase. Literature values for dispersive and polar components of liquid surface tensions were used to determine surface energies [31].

\subsection{Microdroplet single fiber pull-out testing}

The healing ability of the fiber-resin interface was investigated with single fiber microdroplet pull-out testing [32]. The testing apparatus was constructed in-house at the US Army Research Laboratory and has a maximum load rating of $200 \mathrm{~g}$ with a sensitivity of $0.01 \mathrm{~g}$ and data collection rate of $1.67 \times 10^{-3} \mathrm{~s}^{-1}$. This apparatus was used in a previous report by Gao et al. [32]. As shown in Fig. 3, a droplet of resin was cured on a single glass fiber. This fiber was embedded within a capillary tube, upon which a cotter pin was affixed to attached the fiber to the testing apparatus. The droplet was then loaded underneath two knife edges to debond the droplet from the fiber [32]. To debond the droplet from the fiber, the fiber was held static while the blades pulled down upon the microdroplet at a rate of $0.01 \mathrm{~mm} \mathrm{~min}^{-1}$.

The black solid load-displacement curve in Fig. 3 is representative of a previously untested single fiber microdroplet specimen. Immediately before droplet debonding, the load reaches its maximum $\left(F_{\text {initial,max }}\right)$. Afterwards, the droplet slides along the fiber, exhibiting a fairly constant frictional force $\left(F_{\text {initial,friction }}\right)$. Testing of a fiber-droplet specimen immediately after interfacial failure gives a load-displacement curve like the blue dashed one in Fig. 3. Although there is still a peak in the load $\left(F_{\text {noheal,max }}\right)$, the peak is representative of the load required to overcome static friction and is not much higher than the frictional force $\left(F_{\text {noheal,friction }}\right)$. Following failure, all specimens were healed for $1 \mathrm{~h}$ at $90^{\circ} \mathrm{C}$ and $12 \mathrm{~h}$ at $22{ }^{\circ} \mathrm{C}$ and then tested to failure again, as shown by the red ${ }^{1}$ dotted line. Note the recovery of most of the load $\left(F_{\text {healed,max }}\right)$ and the comparable frictional force $\left(F_{\text {healed,friction }}\right)$. Healing efficiency is defined by the following equation:

$\eta=\frac{\left(F_{\text {healed,max }}-F_{\text {healed,friction }}\right)-\left(F_{\text {noheal,max }}-F_{\text {noheal.friction }}\right)}{\left(F_{\text {initial,max }}-F_{\text {initial.friction }}\right)-\left(F_{\text {noheal,max }}-F_{\text {noheal.friction }}\right)}$

Eq. (1) differs greatly from the traditional healing efficiency definition of the ration of the healed to initial maximum force:

$\eta=\frac{F_{\text {healed,max }}}{F_{\text {initial,max }}}$

The decision to deviate from Eq. (2) stems from a desire to develop a healing efficiency definition in which any positive healing efficiency indicates recovery of properties at the interface. Eq. (1) is a conservative measure of healing efficiencies that discounts for frictional and inertial forces. Frictional forces are removed through the use of the expressions ( $\left.F_{\text {healed,max }}-F_{\text {healed,friction }}\right)$ and $\left(F_{\text {initial,max }}-F_{\text {initial,friction }}\right)$. We assume that the peak in unhealed force represents the force required to overcome the inertia of the microdroplet. Therefore, this force is removed from the healing efficiency values through the use of the expression $\left(F_{\text {noheal,max }}-F_{\text {noheal,friction }}\right)$ in the numerator and denominator. The effect of using Eq. (1) instead of Eq. (2) is that healing efficiencies are significantly lowered. However, any specimen that provides a positive healing efficiency has recovered properties through either mechanical or chemical bonding at the interface as a result of the healing procedure.

Interfacial shear strength (IFSS) values were also calculated for each fiber-resin combination tested. Eq. (3) describes IFSS where $\tau_{s}$ is IFSS, $d_{\text {fiber }}$ is the fiber diameter and $l$ is the embedded length of resin.

\footnotetext{
${ }^{1}$ For interpretation of color in Fig. 3, the reader is referred to the web version of this article.
} 


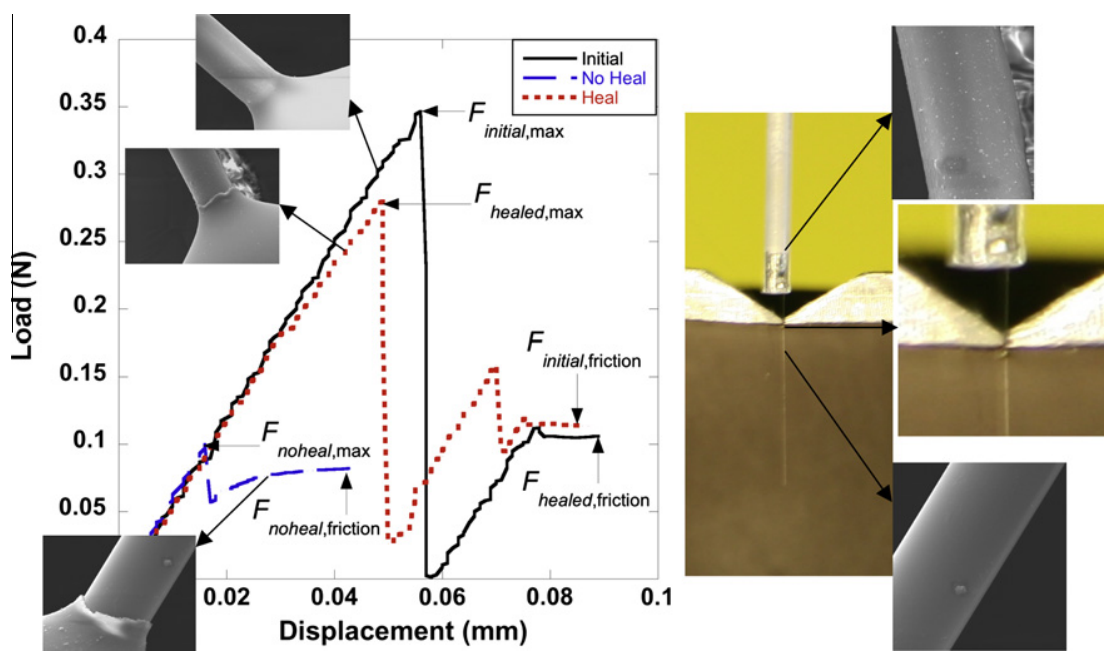

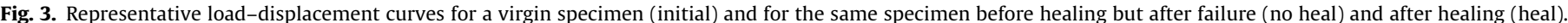

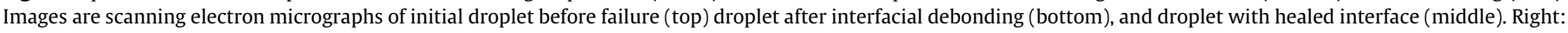

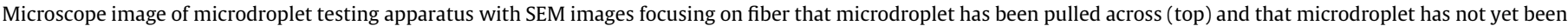
pulled across (bottom).

$\tau_{s}=\frac{F_{\text {initial }, \text { max }}}{\pi d_{\text {fiber }} l}$

\section{Results and discussion}

\subsection{Thermomechanical polymer characterization}

To define the polymer networks being considered, $w_{\text {monomer }}$ represents the weight fraction of the epoxy monomer in the mixture of monofunctional monomers bearing the epoxy group (i.e. not including the amine curing agent or difunctional epoxy). Glass transition temperatures $\left(T_{g}\right)$ were determined for various polymer formulations via DSC. The Fox Equation, which describes the $T_{g}$ of a multicomponent polymer as a function of relative amounts, was used to fit the experimental $T_{g}$ data:

$\frac{1}{T_{g}}=\frac{w_{a}}{T_{g, a}}+\frac{w_{b}}{T_{g, b}}$

In the case of the DGEBA-FGE-PGE-PACM systems, $w_{a}$ is the weight fraction of FGE and $w_{b}$ is the weight fraction of PGE as compared to the total weight of monofunctional epoxide-bearing monomers (FGE and PGE). $T_{g, a}$ corresponds to the $T_{g}$ of a system containing a 6:4 weight ratio of DGEBA and FGE with a stoichiometric amount of PACM, while $T_{g, b}$ corresponds to the $T_{g}$ of a system with the same cross-link density as the 6:4 DGEBA:FGE system, but containing PGE instead of FGE. Fig. 4 shows the $T_{g}$ results fit to Eq (3). $T_{g}$ values are in good agreement $\left(R^{2}=0.984\right)$ with the Fox Equation. The large error bars can be attributed to the small temperature variation $\left(23^{\circ} \mathrm{C}\right)$ observed between the pure FGE system and the pure PGE system. All standard deviations are less than $10{ }^{\circ} \mathrm{C}$ and are primarily the result of testing error. Slight variations in materials, in particular water content of the DGEBA resin, could result in off-stoichiometry formulations and affect $T_{g}$ values [27]. Since the Fox Equation assumes uniform mixing, it can be inferred that the networks were relatively homogeneous. Indeed, no visible signs of phase separation were apparent, as all of the samples studied were optically transparent.

\subsection{Glass characterization}

Fig. 5 shows typical spectra for APS and BMI functionalized glass surfaces. APS glass has been silinated, while BMI glass is

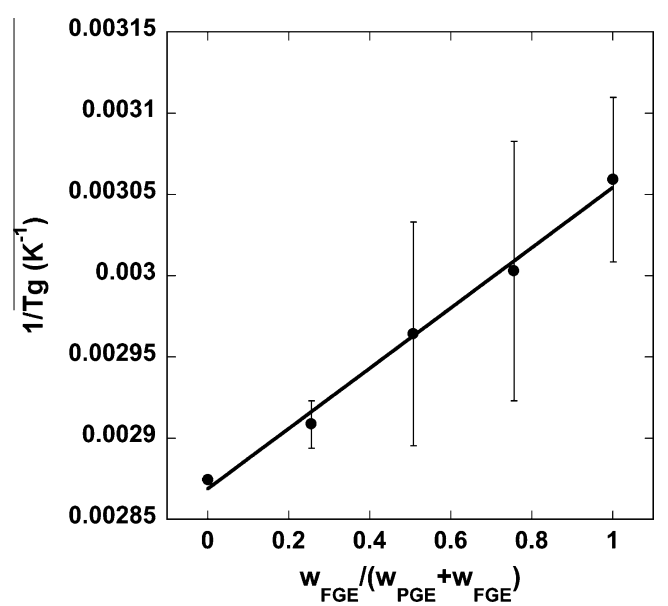

Fig. 4. Effect of FGE loading on $T_{g}$. All networks have the same cross-link density.

APS glass that has been reacted with BMI. The characteristic amine peak is visible near $3469 \mathrm{~cm}^{-1}$ in the APS spectrum but not in the BMI spectrum, indicating that APS glass possessed amine functional groups that were consumed by Michael Addition with maleimides [33]. Additionally, the maleimide spectrum contains a broad peak that is consistent with maleimide $=\mathrm{C}-\mathrm{H}$ stretching at $3100 \mathrm{~cm}^{-1}$ and a peak at $1140 \mathrm{~cm}^{-1}$ that corresponds to maleimide $\mathrm{C}-\mathrm{N}-\mathrm{C}$ stretching.

Contact angles were measured and surface energies were calculated for slides and fibers to demonstrate that similar properties can be accomplished on the surfaces of glass slides as well as fibers. Surface energies are very close between slides and fibers that underwent the same functionalization. Furthermore, there is a noticeable difference between plain glass (Fiber $=46.5 \mathrm{~m} \mathrm{~N} \mathrm{~m}^{-1}$, Slide $=54.2 \mathrm{mN} \mathrm{m}^{-1}$ ) and functionalized, although amine(Fiber $=29.2 \mathrm{~m} \mathrm{~m}^{-1}$, Slide $=33.2 \mathrm{mN} \mathrm{m}^{-1}$ ) and maleimide-functionalized glass (Fiber $=36.8 \mathrm{mN} \mathrm{m}^{-1}$, Slide $=32.7 \mathrm{mN} \mathrm{m}^{-1}$ ) have very similar surface energies. For slides and fibers, the dispersive component of surface energy remained relatively constant for the amine- and maleimide-functionalized surfaces. However, the polar component for maleimide-functionalized glass was greater than that of amine-functionalized glass. 

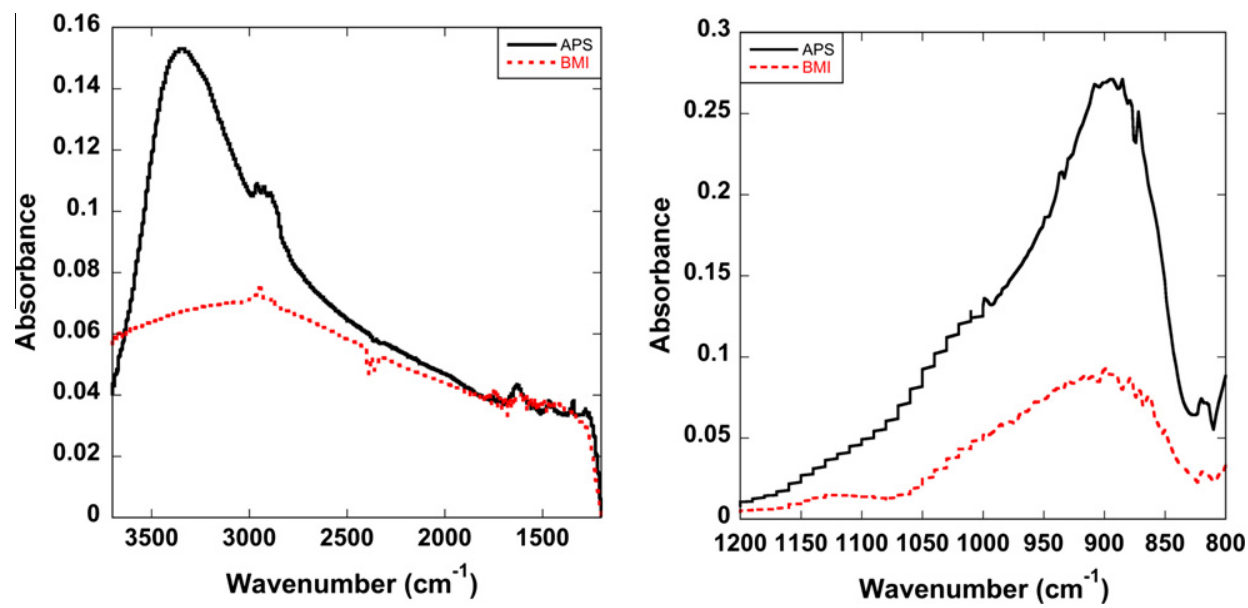

Fig. 5. ATR-FTIR spectra of amine-functionalized (APS) and maleimide-functionalized (BMI) glass slides.

\subsection{Microdroplet single fiber pull-out testing}

Healing of the glass-polymer interface was evaluated with single fiber microdroplet pull-out testing. To explore the effect of displacement on healing, microdroplets were displaced a given amount between 0.01 and 1.2 microdroplet diameters prior to healing. These results are presented in Fig. 6.

It appears that there is no significant dependence of healing efficiency on displacement. The square of the Pearson product moment correlation coefficient, $r^{2}$, is 0.0198 , which shows a very low significance in the relationship between displacement and healing efficiency. One-way ANOVA did not reject the null hypothesis that there is no relationship between displacement and healing efficiency. With an $f$-value of 0.00235 , there is no confidence level for which this null hypothesis would be rejected; therefore, there is no relationship between displacement and healing efficiency, with a high level of confidence. The average healing efficiency of all points was $46.8 \pm 33.7 \%$. The high standard deviation results from scatter in the data. Scatter is understandable, given that strength values are the result of the statistical probability of a given number of bonds cleaving under a specific force. The statistical nature of intimate contact may compound the variability from covalent bonding, resulting in increased scatter. Future work includes understanding the roles that covalent and mechanical bond- ing play in the initial and healed system. Two points were identified as outliers as they were more than two standard deviations away from the average. Removing these values gave an average healing efficiency of $41.2 \pm 22.9 \%$ with $r^{2}=0.0064$.

Scanning electron microscopy was used to better understand the behavior of this system during failure and healing. Upon analysis of images of the trailing and leading edges of the fiber in Fig. 3, it appears that friction of the droplet moving along the fiber caused pieces of the droplet at the droplet-fiber interface to physically degrade. These pieces were left along the surface of the fiber and resulted in some gaps between the droplet and fiber. However, given that healing efficiency does not depend on displacement before healing, it seems that these pieces were broken off of the droplet during the initial failure and remain as physical artifacts.

Droplet diameters were limited to $150-250 \mu \mathrm{m}$ because it was observed that healing efficiency was not dependent on droplet diameter over this range. Additionally, the ratio of the maximum load to diameter is relatively constant in this range. Below and above this range, the ratio dropped off sharply. For smaller droplets, this could be the result of greater effects of the edge of the droplet, while large droplets could experience a decrease in maximum load because the droplets become less spherical and more elongated as diameter increases. Larger droplets also tend to not be centered on the fiber.
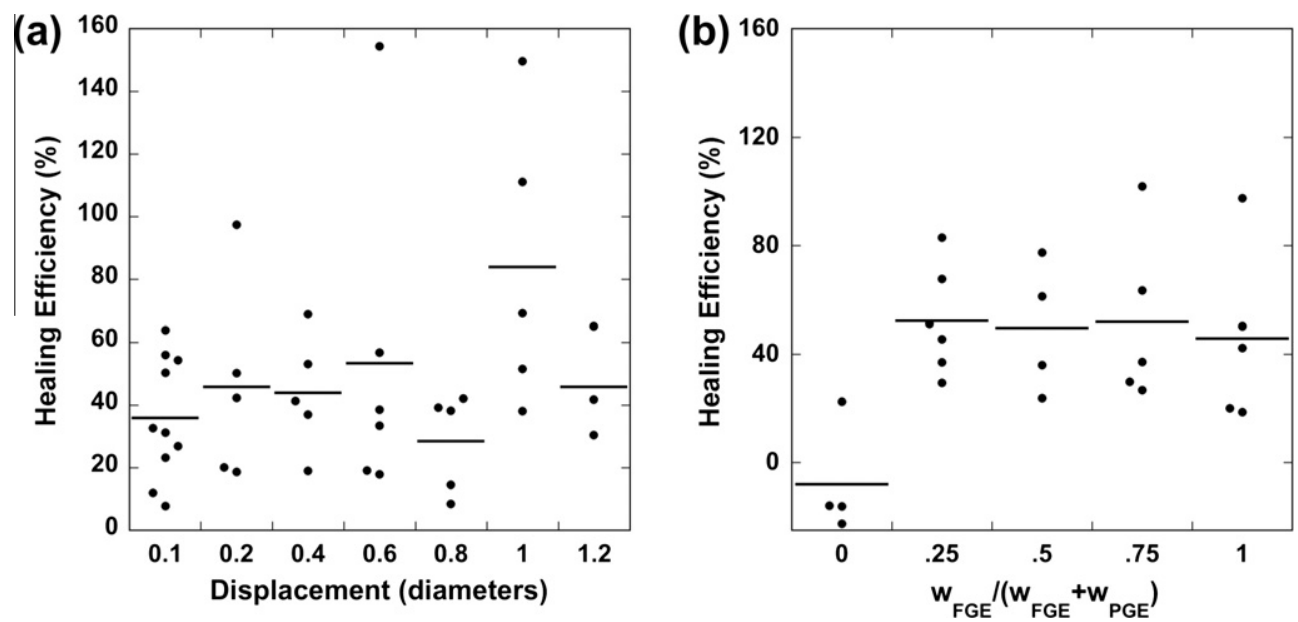

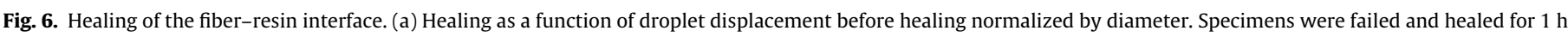

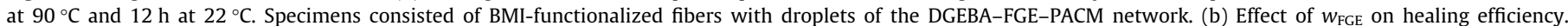

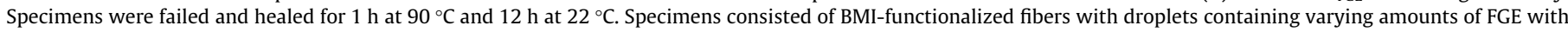
the remainder made up of PGE. Each point represents a data point. Lines indicate averages for each condition. 


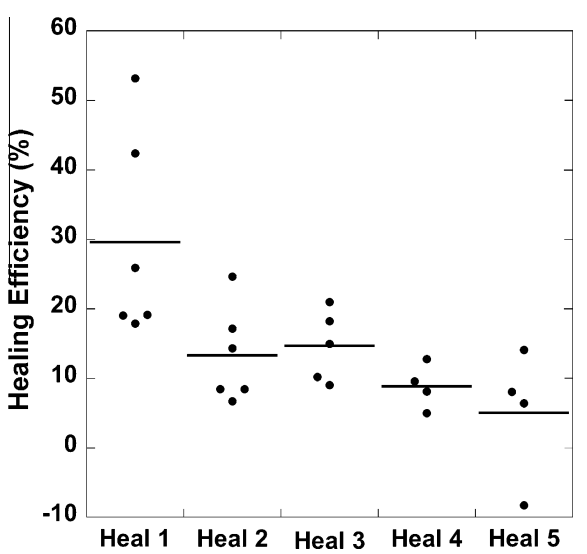

Fig. 7. Healing over multiple cycles. Specimens were failed and healed for $1 \mathrm{~h}$ at $90{ }^{\circ} \mathrm{C}$ and $12 \mathrm{~h}$ at $22^{\circ} \mathrm{C}$. Specimens consisted of BMI-functionalized fibers with droplets of DGEBA-FGE-PACM. Each point represents a data point. Lines indicate averages for each healing cycle.

It is interesting to note that in many cases, there are two groups of healing efficiency values: one that is aggregated around $15-20 \%$ and one that is much higher. We believe that the lower set of droplets represent cases where healing was incomplete. One possibility in these cases is that the edges of the microdroplet were significantly damaged during interfacial failure, thereby decreasing the embedded length available for healing. Future work will include investigating this phenomenon and determining a way to eliminate these data points.

Systems containing just one type of Diels-Alder functional group (furan or maleimide) were selected as controls. The two controls were amine-functionalized fibers with droplets of the furanfunctionalized network (AF) and maleimide-functionalized fibers with droplets of the furan-free network (BP). All droplets were displaced 0.2 diameters before healing. The AF and BP systems demonstrated $9.6 \pm 15.5 \%$ and $-8.0 \pm 20.6 \%$ healing efficiency. In both cases the control systems demonstrated much lower healing efficiency than the base healing system. One possible explanation for healing in the control systems is that increasing the temperature above the polymer network's $T_{g}$ could result in mechanical interlocking with roughness and voids on the fiber surface. All of the thermosetting networks investigated have $T_{g}$ values within a $15^{\circ} \mathrm{C}$ range, so any healing imparted by mechanical interlocking should be relatively constant throughout the systems.

To explore the role that furan concentration plays in interfacial bonding, polymer networks of identical cross-link density but varying furan content were developed and evaluated with single fiber microdroplet pull-out testing. All fibers tested were maleimide functionalized. Healing results are shown in Fig. 6. As long as there was furan in the network, furan content did not play a role in healing efficiency for the amounts investigated, suggesting that the interfacial concentration of furan is much greater than the interfacial concentration of maleimide. A furan concentration of 0.4 furan molecules per $\mathrm{nm}^{2}$ of the polymer surface was calculated based on network structure for the lowest concentration furan-containing system $\left(w_{F G E} /\left(w_{F G E}+w_{P G E}\right)=0.25\right)$, indicating that maleimide concentration on the surface is lower than this value. Since incorporation of FGE reduces $T_{g}$, the potential exists that higher $T_{g}$ networks could have comparable healing efficiencies. Future work will investigate ways to control the maleimide concentration and how this parameter affects healing and mechanical properties.

The ability of the interface to heal multiple times was investigated because it is desirable for a healing system to be effective more than once. Healing efficiency decreased in general with each healing cycle, plateauing around the third healing cycle at a healing

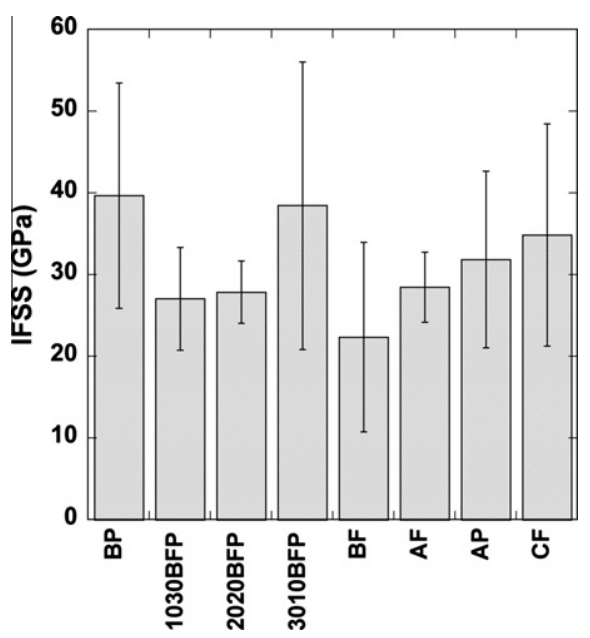

Fig. 8. Interfacial shear strength (IFSS) values for various microdroplet-fiber conditions. $\mathrm{BP}=\mathrm{BMI}-$ functionalized fibers, droplets with DGEBA-PGE-PACM; $1030 \mathrm{BFP}=\mathrm{BMI}$-functionalized fibers, droplets with $w_{\mathrm{FGE}} /\left(w_{\mathrm{FGE}}+w_{\mathrm{PGE}}\right)=0.25$; $2020 \mathrm{BFP}=\mathrm{BMI}-$ functionalized fibers, droplets with $w_{\mathrm{FGE}} /\left(w_{\mathrm{FGE}}+w_{\mathrm{PGE}}\right)=0.5$; $3010 \mathrm{BFP}=\mathrm{BMI}$-functionalized fibers, droplets with $w_{\mathrm{FGE}} /\left(w_{\mathrm{FGE}}+w_{\mathrm{PGE}}\right)=0.75$; $\mathrm{BF}=\mathrm{BMI}-$ functionalized fibers, droplets with DGEBA-FGE-PACM; AF = APS-functionalized fibers, droplets with DGEBA-FGE-PACM; AP = APS-functionalized fibers, droplets with DGEBA-PGE-PACM; CF = cleaned fibers, droplets with DGEBA-FGEPACM.

efficiency of $\sim 10 \%$. Results are shown in Fig. 7. However, healing was carried out for five cycles successfully in three of the five cases, showing that healing is possible at least five times. The decrease in healing efficiency most likely resulted from the interfacial damage of multiple delaminations.

IFSS results are presented in Fig. 8. All values are in the same range; therefore, the functionalization of the fibers as well as the network does not adversely affect IFSS.

\section{Conclusions}

We have developed a thermosetting network with furan functionality and tailorable $T_{g}$ as well as a glass sizing with maleimide functionality. Glass with this sizing reacts covalently with the furan-functionalized polymer matrix. Since the bonding at the glasspolymer interface is reversible, debonding of the glass fibers can be healed and mechanical properties can be recovered. Remendability has been evaluated with single fiber microdroplet pull-out testing of maleimide-functionalized glass fibers in the furan-functionalized network. Healing efficiency was not affected by the distance of displacement, with an overall average of $41 \%$ healing efficiency. Healing efficiency was shown to be independent of furan loading at the concentrations investigated. Multiple heals were possible and up to five healing cycles were investigated.

The sizing procedure for glass fibers can easily be scaled up to production levels and the temperatures for healing are low enough that healing can be performed on site. As the composites industry continues to expand, the need for more durable and easily repaired systems will only increase.

Future work includes increasing the concentration of maleimide groups on the glass fiber, which should increase healing efficiency, as well as investigating the roles of network $T_{g}$ and healing conditions on healing. It is anticipated that glass-reinforced composites with maleimide-functionalized glass and a furan-functionalized network will demonstrate reversible covalent bonding at the network-reinforcement interface. Additionally, we hope to address the cause of scatter and investigate methods to reduce this variability. We plan to prepare composites using this fiber-network 
system and investigate the ability to heal delamination in a realworld system.

\section{Acknowledgements}

The authors from Drexel University wish to acknowledge the US Army Research Laboratory for financial support under the Army Materials Center of Excellence Program, Contract W911NF-06-20013. Amy Peterson is supported in part by a National Science Foundation Graduate Research Fellowship. The authors thank the US Army Research Laboratory for use of the microdroplet single fiber pull-out testing apparatus.

\section{References}

[1] Wu HF, Dwight DW, Huff NT. Effects of silane coupling agents on the interphase and performance of glass-fiber-reinforced polymer composites. Compos Sci Technol 1997;57:975-83.

[2] Jensen RE, Palmese GR, Mcknight SH. Viscoelastic properties of alkoxy silaneepoxy interpenetrating networks. Int J Adhes Adhes 2006;26:103-15.

[3] Brown EN, White SR, Sottos NR. Retardation and repair of fatigue cracks in a microcapsule toughened epoxy composite - part I: manual infiltration. Compos Sci Technol 2005;65(15-16):2466-73.

[4] Chen B, Dillard D, Dillard J, Clark R. Crack path selection in adhesively bonded joints: the roles of external loads and specimen geometry. Int J Fract 2002;114(2):167-90.

[5] Diels O, Alder K. Synthesen in der hydroaromatischen Reihe. Justus Liebigs Ann Chem 1928;460(1):98-122.

[6] Diels O, Alder K. Synthesen in der hydro-aromatischen Reihe, II. Mitteilung: Über Cantharidin. Ber Deut Chem Ges 1929;62(3):554-62.

[7] Stille J, Plummer L. Polymerization by the Diels-Alder reaction. J Org Chem $1961 ; 26(10): 4026-9$.

[8] Chen X, Dam M, Ono K, Mal A, Shen H, Nutt S, et al. A thermally re-mendable cross-linked polymeric material. Science 2002;295(5560):1698-702.

[9] Chen X, Wudl F, Mal A, Shen H, Nutt S. New thermally remendable highly cross-linked Polymeric materials. Macromolecules 2003;36(6):1802-7.

[10] Peterson AM, Jensen RE, Palmese GR. Reversibly cross-linked polymer gels as healing agents for epoxy-amine thermosets. ACS Appl Mater Interf 2009;1(5):992-5.

[11] Peterson AM, Jensen RE, Palmese GR. Room-temperature healing of a thermosetting polymer using the Diels-Alder reaction. ACS Appl Mater Interf 2010;2(4):1141-9.

[12] Chujo Y, Sada K, Saegusa T. Reversible gelation of polyoxazoline by means of Diels-Alder reaction. Macromolecules 1990;23(10):2636-41.

[13] Canary S, Stevens M. Thermally reversible crosslinking of polystyrene via the furan-maleimide Diels-Alder reaction. J Polym Sci A Polym Chem 1992;30(8):1755-60.
[14] Wagener KB, Engle LP. Thermally reversible polymer linkages. II. Linear addition polymers. J Polym Sci A Polym Chem 1993;31(4):865-75.

[15] Watanabe M, Yoshie N. Synthesis and properties of readily recyclable polymers from bisfuranic terminated poly(ethylene adipate) and multimaleimide linkers. Polymer 2006;47(14):4946-52.

[16] Zhang Y, Broekhuis AA, Picchioni F. Thermally self-healing polymeric materials: the next step to recycling thermoset polymers? Macromolecules 2009;42:1906-12.

[17] Gousse C, Gandini A, Hodge P. Application of the Diels-Alder reaction to polymers bearing furan moieties 2. Diels-Alder and retro-Diels-Alder reactions involving furan rings in some styrene copolymers. Macromolecules 1998;31:314-21.

[18] Mcelhanon JR, Russick EM, Wheeler DR, Loy DA, Aubert JH. Removable foams based on an epoxy resin incorporating reversible Diels-Alder adducts. J Appl Polym Sci 2002;85(7):1496-502.

[19] Gandini A, Belgacem MN. Furans in polymer chemistry. Prog Polym Sci 1997;22:1203.

[20] Engle LP, Wagener KB. A review of thermally controlled covalent bond formation in polymer chemistry. J Macromol Sci: Rev Macromol Chem Phys 1993;33(3):239-57.

[21] Nandivada H, Jiang X, Lahann J. Click chemistry: versatility and control in the hands of materials scientists. Adv Mater 2007;19(17):2197-208.

[22] Gandini A. Furans as offspring of sugars and polysaccharides and progenitors of a family of remarkable polymers: a review of recent progress. Polym Chem 2010;1(3):245.

[23] Bergman SD, Wudl F. Mendable polymers. J Mater Chem 2008;18(1):41.

[24] Blaiszik BJ, Kramer SLB, Olugebefola SC, Moore JS, Sottos NR, White SR. Selfhealing polymers and composites. Annu Rev Mater Sci 2010;40:19.1-19.33.

[25] Williams H, Trask RS, Bond I. Self-healing sandwich panels: restoration of compressive strength after impact. Compos Sci Technol 2008;68(1516):3171-7.

[26] Blaiszik BJ, Baginska M, White SR, Sottos NR. Autonomic recovery of fiber/ matrix interfacial bond strength in a model composite. Adv Funct Mater 2010.

[27] Palmese GR, McCullough RL. Effect of epoxy-amine stoichiometry on cured resin material properties. J Appl Polym Sci 1992;46(10):1863-73.

[28] Asloun E, Nardin M, Schultz J. Stress transfer in single-fibre composites: effect of adhesion, elastic modulus of fibre and matrix, and polymer chain mobility. J Mater Sci 1989;24(5):1835-44.

[29] Pitkethly M, Doble J. Characterizing the fibre/matrix interface of carbon fibrereinforced composites using a single fibre pull-out test. Composites 1990;21(5):389-95.

[30] Hopewell JL, George GA, Hill DJT. Quantitative analysis of bismaleimidediamine thermosets using near infrared spectroscopy. Polymer 2000;41:8221-9.

[31] Kaelble DH, Cirlin EH. Dispersion and polar contributions to surface tension of poly (methylene oxide) and Na-treated polytetrafluoroethylene. J Polym Sci A2 Polym Phys 1971;9:363-8.

[32] Gao X, Jensen R, Li W, Deitzel J, Mcknight S, Gillespie J. Effect of fiber surface texture created from silane blends on the strength and energy absorption of the glass fiber/epoxy interphase. J Compos Mater 2008;42(5):513-34.

[33] Shen Z, Schlup JR. Mid- and near-infrared spectroscopic investigations of Nphenylmaleimide (NPM)/amine reactions. J Appl Polym Sci 1998;67:267-76. 